\title{
Comparing the Teaching Methods' Effect (Traditional and Modern) on Problem-Solving Ability in 4 to 6 Years-Old Students of Nursery Schools in 12 Cities of Tehran Province
}

\author{
Shahrzad Sarkhosh ${ }^{1}$
}

HoseinAli Taghi Pour2

\author{
${ }^{1}$ Msc of Nurture Sciences, Lesson Planning field; Chaloos Azad University; Email: maghale95@gmail.com \\ 2Supervisor, Phd of Nurture Sciences, Lesson Planning field; Chaloos Azad University
}

\author{
Doi:10.5901/jesr.2016.v6n2p63
}

\section{Abstract}

The purpose of this research is to compare the teaching approaches (traditional and modern) and their effects on the abilities of the four and six year old students of nursery schools in 12 cities of Tehran province. The method for this approach is regarding the nature of the approaches and their purposes, thus, a semi-test or a semi-experimental the statistic population in this survey is consisting of all the students aged 4 and 6 in 12 districts in Tehran. Also, the samples for the tests in every group and in the control group is consisting of 12 people.we should stress that the survey consists of two groups, the test group 20 people, and the control group 20. The sampling approach is a gradual or level-based one.to measure the students' abilities in problem solving aged 4 to 6 , a questionnaire has been used consisting 21 cases that measures different ways of problem solving. The data in this project (survey) have been analyzed bused on two levels of descriptive and analogy, and variance analytic test has been used, too. Based on the findings of the project, there have been significant differences between the traditional and modern methods of teaching about problem solving abilities of the children aged 4 to 6 in nursery schools of the 12th educational district of Tehran. The significant result shows that the scores gotten by the students (test group) taught through the modern method have been higher than the students (control group) scores taught by the traditional method.

Keywords: educational methods (teaching methods), nursery school traditional, modern, ability to solve problems.

\section{Introduction}

Educational systems have rapidly progressed simultaneously with the daily developing sciences and technologies. They have also been pioneers for enriched thoughts and ideas. So, changing curricular purposes in educational syllabuses, educational materials, educational methods, and thoroughly speaking, changing the teaching and learning approaches are inevitable facts that cannot be ignored. On the other hand, educational centers have accepted heavier and harder responsibilities about community and families. In the past, educational systems mostly emphasized mental and cognitive learning's, but these days, thorough and personal growth is one of the first and main purposes and one of the developing aspects of the child's character and his or her cognitive and social aspects. (Afzali, 1390).

Caring about children not only guarantees their health during their childhood, but also during their adulthood. Ericson (social growth theorist), introduces 3 to 5 years of children's age or pre- school years as a creative period.

Facing sins.it means that the children's world spreads and they learn to cope with the challenges and learn to be having purpose fully. Friedrich Froebel the founder of kindergarten believes that the pre-school period is a basic step in education and training ladder (Abri etal. 1390).

In addition to that, children learn most of their cognitive and social skills in their childhood. They learn to thrust on other adults, except their parents and they enjoy this trust. They learn to relate with others, oppose with them, share things, associate with others and also prove themselves. They learn to be a member of a group and share group activities, learn to adopt the group expectations and trust other people's rights and emotions. In fact, children's behaviors and reactions while playing games, depending on the parents and their being cared by the parents and their relationships towards family and friends shows their social growth and evolution. Also, they learn to solve their problems facing them by using the cognitive and thinking skills (Kaplan 2000, translated by Firoozbakht 1386).

People do solve their facing problems in their daily lives. Some of these problems are easy to solve, but others need complicated mind activities. In case important life problems remain unsolved in people's lives, they will face a lot of challenges. Problem solving abilities can pare the way much more effective. Children are not exceptional in this case and need these abilities to solve their complicated problems. Thus, experts, specialists and responsible authorities should 
train children in this respect before their school time. This is because the pre-school period is of their golden era whose trainings significantly affect their thorough life. Thus in this research, there is an emphasis on the traditional and modern methods of teaching the abilities to solve children's problems.

\section{Stating a Problem}

The progress of every society is depending on its educational power, and the function of each educational system is evaluated through its students and learned people's educational purposes (jafari kookhaloo and hamidi'1387). In this respect, education in the early childhood period is paid attention to by a vast number of education authorities, training people, psychologists, philosophers and physiology scientists, biologists and different professional men and women experts. These days, most of the thinkers believe that the years before school are the most fruitful ones for learning educational purposes and believe that the young children learn things much faster that what they learn later. Also, these learning's and findings and their primary learned abstracts are much more durable than the future ones (kakia, 1388).

Educational purposes in every level, regarding pre-school ones, are essentially determining the educational methods and programs. Traditional education systems through which the trainers only give inactive or passive information has risen from an only one - dimensional aspect. This means the educational responsibilities are only transferring the information to the learners. On the other hand, the modern educational systems emphasize on the active participation of the learners and their complete personal dimensions. The teacher or the tutor is not only the transferor of the knowledge, but also the simplifier of the educational processes, the cognitive, emotional and behavioral characteristics (jafari kookhaloo and hamidi ,1387).

One of the purposes in the modern educational systems is to pay attention to the children and teenagers' social skills. Social skills consist of a collection of some abilities that begin and preserve positive and useful social relationships and develop peer group's friendship and intimacy. They provide satisfaction in the learning environments and permit the people to adopt the conditions, so they accept the demands of the social environment (Gresham and etal.2006).

Erdem (2009) has gotten some results in his research that the mathematical methods depending on the active and sharing methods have been together with increasing much better students' and teacher's relational skills and also developing the students' thoughts .

In this respect, one of the cognitive abilities which are highly important is the children's problem solving ability. Solving problems is a vital competence for the present life and most of the societies believe that there should be more emphasis on the abilities of problem solving.

On the whole, problem solving abilities refer to the person's creative processes of cognitive and behavioral aspects that the people use to create, and or assign solutions to the daily problems. In the personal and social progresses and decreases the spiritual sadness. In this respect, among the teachers' duties and educational authorities' responsibilities are to recognize the problems to be solved by the children. In this process, the children are helped to think about their own problem, find different ways and select the best ones to solve their problems in addition to this, the children learn to deal with their problems in a way that ignore anxiety and deal with their failures suitably (twerski \& shwartz, 2005).

As the social and cognitive skills are important in problem solving, the necessity to improve these skills social skills and getting abilities to solve problems many institutions, organizations and other agencies and authorities have essential roles. One of these institutions is the education one, which is the nursery school.it has a significant effect on developing human skills. Although most of scientists and experts regarding children social and cognitive developers have accepted and acknowledged this fact, they have sometimes ignored it because it has been out of their duty domains. They have stressed out that these skills should be held to the Institutions such as families and other social and formal ones like schools. In this respect, this research tries to survey and compare the effect of the traditional and modern methods on the students aged 4 to 6 in nursery schools of the $12^{\text {th }}$ district in Tehran.

\section{The Research Purposes}

\subsection{The overall purpose}

To survey the effect of the traditional and modern educational methods on problem solving of the students aged 4 to 6 . 


\subsection{The detail purpose}

To survey the effect of the traditional and modern educational methods on problem- oriented abilities of the children aged 4 to 6 .

To survey the effect of the traditional and modern educational methods on activity - oriented abilities of the children aged 4 to 6 .

To survey the effect of the traditional and modern educational methods on quality - oriented abilities of the children aged 4 to 6 .

\section{The Research Methodology}

The methodology to do this research regarding its subject and nature of the purpose is a semi- test or a semi experimental one since there is no possibility to completely handle the variables.

The methodology of this research is a semi -experimental one and since there was no possibility of random student selection, the primary and the final test plans were used with the witness group.

In every test or control group, the primary and final tests were performed, but only the test group was affected by the independent variable which was regarded by the researcher and the control group was regardless of this fact.

In this research, too, the primary test or the pre- test was performed in both test group and control group. Finally, after eight weeks final test or post- test was performed on both groups.

The statistical population in this project consists of all the children aged 4 to 6 in the $12^{\text {th }}$ district of Tehran. The number of students is 1347. Also, the sample for every test is consisting of 40 people. To measure the children's ability to solve their problems, a questionnaire consisting of 21 cases that tested different ways of solving problems. The data in the research were analyzed in two ways: descriptive and analogic. In the descriptive way, the findings were summarized using descriptive charts. For the quantitative data in the research, frequency charts were drawn, medians were taken, variances and deviations were also measured. And, in the descriptive level, there was a through comparison done. In the analogy level, also an analytic and a two - way variance test was used.

The sample was consisting of 60 people, 30 in the test group and 30 in the control group.

The sampling in this test was a gradual or a leveling one. The people being tested were selected based on a hierarchy, from the bigger units to the smaller ones. They were selected from different units, levels and areas, the students in the nursery schools, one at a time, two classes of each and all aged 4 to six.

\subsection{Methodology for measuring reliability of the research}

Before the test being done, the validity of the questionnaire and the test had been surveyed and analyzed by some university teachers in the psychology and social sciences departments. It was done to identify and prove the correctness and validity of the cases, and to equalize the premises with the suggested ideas. As a matter of fact, this survey is done to identify whether the test measures what is planned to be measured.

\subsection{Methodology for measuring reliability of the research}

To measure the probability questions of the test, Cronbach Alpha was used. The final probability was $78 \%$, which is an acceptable one.

\section{The Method for Gathering Data}

To collect the data in this research, two ways were used: the library research data and the open- area.

The library research data were by reading books, articles and other sources related to the subject in this project. The open- area data were gathered by the tests that the students in this case were taken. One week before the pre- test, there were some briefing meetings held to brief and justify the teachers of the classes.

The teachers then were trained and justified by the usages of these modern methods. These meetings were consisting of 16 sessions, every one consisting of 30 minutes. The main responsibility of the teachers in these cases were to make the lesson plans, to guide the students, to provide the necessary facilities and to evaluate and observe the cases and the students feedback. 


\subsection{The methodologies to analyze the data}

The data in this project were analyzed in two levels; Descriptive and analogy. In the descriptive level there was a chart used to summarize the data. For the quantity data of the project, the frequency charts, medians, variance and deviance charts were drawn. In the analogy level, the Manco test was used.

The analysis of the data was done in three ways: first, identifying the data and preparing them for the analysis. Second, doing the validity and probability tests. And finally, analyzing the data after them together with the final discussion on them.

Describing data

\begin{tabular}{ccc}
\hline Percentage & Frequency & Age \\
\hline 45.00 & 18 & 4 years \\
\hline 35.00 & 14 & 5 years \\
\hline 20.00 & 8 & 6 years \\
\hline 100 & 40 & Total \\
\hline
\end{tabular}

\subsection{The chart to survey the age in the samplings}

The chart shows the sampling population. As the values show, 4500 (45\%) are aged 4, 3500(35\%) are aged 5 and $2000(20 \%)$ are aged 6.

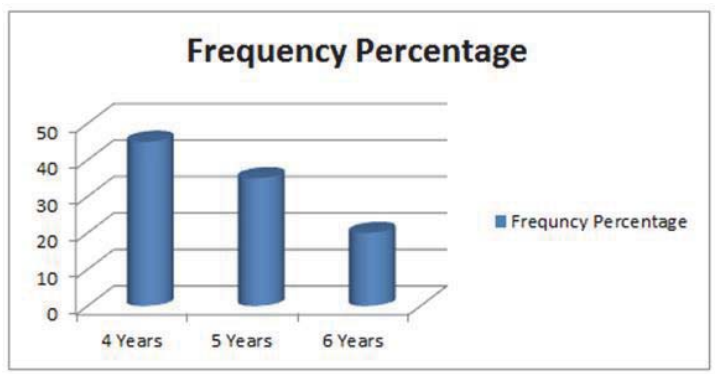

\subsection{The surveying chart for age in the statistics sampling}

The descriptive statistics chart between Subjects Factors

\begin{tabular}{|c|c|l|c|}
\hline & & Value Label & $\mathrm{N}$ \\
\hline \multirow{3}{*}{$\mathrm{g}$} & 1 & Control & 30 \\
\cline { 2 - 4 } & 2 & Examination & 30 \\
\hline
\end{tabular}

This chart shows the number of people in the test, consisting of two groups of 30 people.

The chart for the number of descriptive statistics

\begin{tabular}{|l|c|c|c|c|c|c|c|}
\hline & N & Range & Minimum & Maximum & Mean & Std. Deviation & Variance \\
\hline pish.mas & 60 & 12,00 & 16,00 & 28,00 & 21,4000 & 3,48459 & 12,142 \\
piash.faal & 60 & 22,00 & 13,00 & 35,00 & 26,3667 & 4,65766 & 21,694 \\
pish.keif & 60 & 7,00 & 16,00 & 23,00 & 19,9000 & 2,29738 & 5,278 \\
pas.mas & 60 & 14,00 & 16,00 & 30,00 & 23,5500 & 4,03974 & 16,319 \\
pas.faal & 60 & 12,00 & 23,00 & 35,00 & 29,7500 & 3,31215 & 10,970 \\
pas.keif & 60 & 11,00 & 16,00 & 27,00 & 21,3500 & 2,67331 & 7,147 \\
Valid N (listwise) & 60 & & & & & & \\
\hline
\end{tabular}

Regarding the chart shown above, the medians in the pre- test of each case has been 21,4000 . The activities have been 26. 3667 , pre- test of the quality has been 19.9000 , the medians for the scores after each one of the test cases has been 
23.5500, the activities has been 29. 7500 and the quality has been 21,3500 .

One- sample Kolmogorov- Smirnov Test

\begin{tabular}{|ll|c|c|c|c|c|c|}
\hline & & pish.mas & piash.faal & pish.keif & pas.mas & pas.faal & pas.keif \\
\hline $\mathrm{N}$ & & 60 & 60 & 60 & 60 & 60 & 60 \\
Normal Parameters ${ }^{2}$ & Mean & 21,4000 & 29,7500 & 19,9000 & 23,5500 & 29,7500 & 21,3500 \\
& Std. Deviation & 3,48459 & 3,31215 & 2,29738 & 4,03974 & 3,31215 & 2,67331 \\
& Absolute &, 154 &, 137 &, 196 &, 119 &, 137 &, 115 \\
Most Extreme Differences & Positive &, 147 &, 090 &, 196 &, 119 &, 090 &, 112 \\
& Negative &,- 154 &,- 137 &,- 161 &,- 111 &,- 137 &,- 115 \\
Kolmogorov-Smirnov Z & & 1,195 & 1,059 & 1,517 &, 925 & 1,059 &, 889 \\
Asymp. Sig. (2-tailed) & &, 115 &, 212 &, 020 &, 359 &, 212 &, 408 \\
\hline
\end{tabular}

As you see in the chart above, This test shows that the scores are not significant $(p=0.555)$ and so the scores they carry a normal frequency and we can use parametric analyses for it.

The descriptive statistics chart between Subjects Factors

\begin{tabular}{|c|c|c|c|}
\hline & & Value Label & $\mathrm{N}$ \\
\hline \multirow{2}{*}{ g } & 1 & Control & 30 \\
\hline & 2 & Examination & 30 \\
\hline
\end{tabular}

The chart above shows the number of people in the test consisting of two groups of 30 people.

The Examining Chart for the Interactions between the Dependent Variable and the Independent Variable Dependent Variable: pas.mas

\begin{tabular}{|l|c|c|c|c|c|}
\hline Source & Type III Sum of Squares & Df & Mean Square & $F$ & Sig. \\
\hline Corrected Model & $575,192^{2}$ & 3 & 191,731 & 27,697 &, 000 \\
Intercept & 255,217 & 1 & 255,217 & 36,868 &, 000 \\
g & 121,118 & 1 & 121,118 & 17,496 &, 000 \\
pish.mas & 167,361 & 1 & 167,361 & 24,176 &, 000 \\
g* pish.mas & 73,391 & 1 & 73,391 & 10,602 &, 002 \\
Error & 387,658 & 56 & 6,922 & & \\
Total & 34239,000 & 60 & & & \\
Corrected Total & 962,850 & 59 & & & \\
\hline
\end{tabular}

a. R Squared $=, 597$ (Adjusted R Squared $=, 576$ )

This chart shows a non- adjacency between the data of the premise of regressions, so it is significant and meaningful, so the premise or theory is not accepted. Anyway, as we surveyed the regression, we can perform the co- variance test analysis. Of course, before that, we survey the cases prior to identifying the relationship between the helping variable and the dependent variable. 


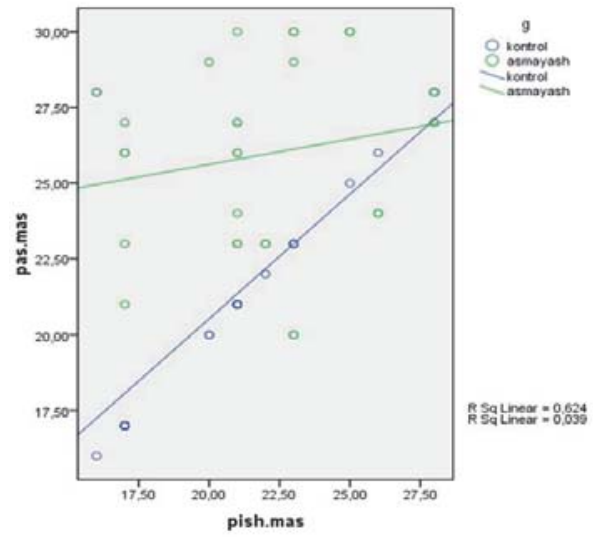

\subsection{The chart to survey the accidental variable and the dependent variable}

The chart shows that the regression lines are not equal or even close to each other. Although the lines being equal or close were part of the co-variance test, not having this case has no problem for our research.

Tests of Between-Subjects Effects

Dependent variable: pas.mas.

\begin{tabular}{|l|c|c|c|c|c|c|}
\hline Source & Type III Sum of Squares & Df & Mean Square & F & Sig. & Partial Eta Squared \\
\hline Corrected Model & $501,801^{a}$ & 2 & 250,901 & 31,019 &, 000 &, 521 \\
Intercept & 268,730 & 1 & 268,730 & 33,223 &, 000 &, 368 \\
pish.mas & 151,385 & 1 & 151,385 & 18,716 &, 000 &, 247 \\
G & 255,805 & 1 & 255,805 & 31,625 &, 000 &, 357 \\
Error & 461,049 & 57 & 8,089 & & & \\
Total & 34239,000 & 60 & & & & \\
Corrected Total & 962,850 & 59 & & & & \\
\hline
\end{tabular}

a. $\mathrm{R}$ Squared $=, 521$ (Adjusted R Squared $=, 504$ )

After the medians are done in the pre-test, the effect of the meaningful factor between the tests were (fc 2,68)=31.6, $p<0.0005 R^{2}$ partial $p=0$ ), so the group asks for a comparison for the data scores to identify any mistakes to get the significant meaningful effect.

The chart for surveying the adjacency between the dependent and independent variables Dependent Variable: pas.keif

\begin{tabular}{|l|c|c|c|c|c|}
\hline Source & Type III Sum of Squares & Df & Mean Square & F & Sig. \\
\hline Corrected Model & $380,390^{a}$ & 3 & 126,797 & 172,094 &, 000 \\
Intercept & 2,709 & 1 & 2,709 & 3,676 &, 060 \\
G &, 780 & 1 &, 780 & 1,059 &, 308 \\
pish.keif & 296,145 & 1 & 296,145 & 401,942 &, 000 \\
$g^{*}$ pish.keif &, 091 & 1 &, 091 &, 123 &, 727 \\
Error & 41,260 & 56 &, 737 & & \\
Total & 27771,000 & 60 & & & \\
Corrected Total & 421,650 & 59 & & & \\
\hline
\end{tabular}

a. R Squared = ,902 (Adjusted R Squared $=, 897$ )

This chart shows a non- balance case in the data and it identifies a significant meaningful adjacent, so the theory or premise is not accepted. As we surveyed the regression slope, we can perform the co-variance analysis test. Of course, before the survey between the variables was done, we used the charts. The chart shows the equal regression lines or close and parallel. 
Although for the lines being parallel or close is of a case in the co- variance test, it's not the only necessary characteristic in this case, so it cannot be a problem.

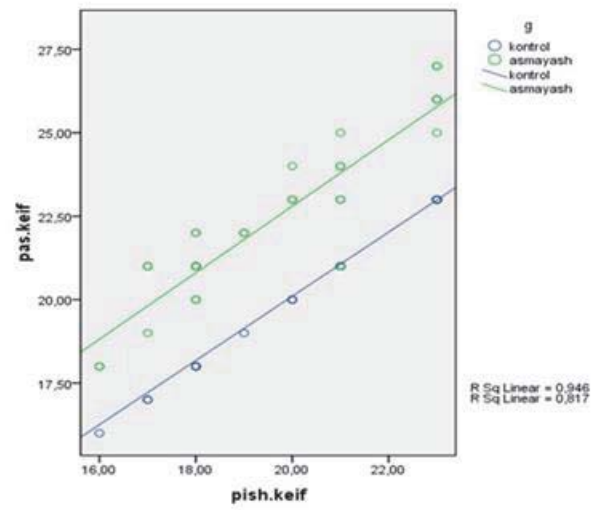

The chart to survey the accidental variable and the dependent variable to assign the quality test.

The Chart to Survey the Premises or Theories of the Variance

Dependent Variable:pas.keif

\begin{tabular}{|c|c|c|c|}
\hline$F$ & df1 & df2 & Sig. \\
\hline 15,326 & 1 & 58 &, 000 \\
\hline
\end{tabular}

In this chart, the theories or premises are surveyed that show a significant meaningful move than $5 \%$. It shows that the reason for the variance error is questioned.

The survey for the adjacency between the dependent and independent variables

\begin{tabular}{|l|c|c|c|c|c|c|}
\hline Source & Type III Sum of Squares & df & Mean Square & $F$ & Sig. & Partial Eta Squared \\
\hline Corrected Model & $380,390^{\mathrm{a}}$ & 3 & 126,797 & 172,094 &, 000 &, 902 \\
Intercept & 2,709 & 1 & 2,709 & 3,676 &, 060 &, 062 \\
G & 0.780 & 1 & 0.780 & 1,059 &, 308 &, 019 \\
pish.keif & 296,145 & 1 & 296,145 & 401,942 &, 000 &, 878 \\
g * pish.keif & $91 \%$ & 1 & $91 \%$ & 0.123 &, 727 &, 002 \\
Error & 41,260 & 56 & 0.737 & & & \\
Total & 27771,000 & 60 & & & & \\
Corrected Total & 421,650 & 59 & & & & \\
\hline
\end{tabular}

a. R Squared $=, 902$ (Adjusted R Squared $=, 897$ )

After the scores were assigned, the test significant factor of the tests was $\left(4(2,68)=1.59, p<0.0005 R^{2}\right.$ partian $(=0.308)$. The median makes were surveyed and suggested and finally we find that the accidental variable is significantly related to the dependent variable.

Surveying the adjacent between the dependent and independent variables Dependent Variable:pas.faa

\begin{tabular}{|l|c|c|c|c|c|c|}
\hline Source & Type III Sum of Squares & df & Mean Square & F & Sig. & Partial Eta Squared \\
\hline Corrected Model & $320,654^{a}$ & 3 & 106,885 & 18,327 &, 000 &, 495 \\
Intercept & 355,627 & 1 & 355,627 & 60,978 &, 000 &, 521 \\
G & 8,091 & 1 & 8,091 & 1,387 &, 244 &, 024 \\
piash.faal & 290,881 & 1 & 290,881 & 49,876 &, 000 &, 471 \\
g piash.faal & 7,939 & 1 & 7,939 & 1,361 &, 248 &, 024 \\
Error & 326,596 & 56 & 5,832 & & & \\
Total & 53751,000 & 60 & & & &
\end{tabular}


Dependent Variable:pas.faa

\begin{tabular}{|l|c|c|c|c|c|c|}
\hline Source & Type III Sum of Squares & df & Mean Square & $F$ & Sig. & Partial Eta Squared \\
\hline Corrected Model & $320,654^{a}$ & 3 & 106,885 & 18,327 &, 000 &, 495 \\
Intercept & 355,627 & 1 & 355,627 & 60,978 &, 000 &, 521 \\
G & 8,091 & 1 & 8,091 & 1,387 &, 244 &, 024 \\
piash.faal & 290,881 & 1 & 290,881 & 49,876 &, 000 &, 471 \\
g * piash.faal & 7,939 & 1 & 7,939 & 1,361 &, 248 &, 024 \\
Error & 326,596 & 56 & 5,832 & & & \\
Total & 53751,000 & 60 & & & & \\
Corrected Total & 647,250 & 59 & & & & \\
\hline
\end{tabular}

a. R Squared $=, 495$ (Adjusted R Squared $=, 468$ )

This chart shows the un-balance between the data from the regression of the supporting theory or premise, so the adjacent is meaningful. In this case, the premise is not affected, because we surveyed the regression. Now, we can perform the co-variance analytic test. Of course, before that we survey the relationship between the helping variable and the dependent variable using the chart.

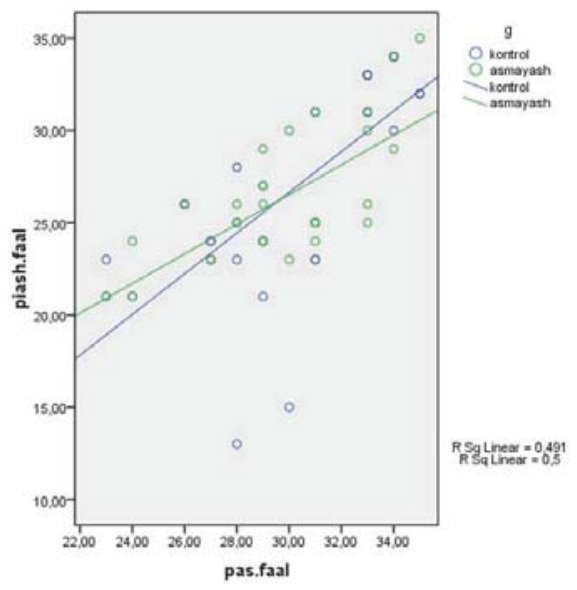

This chart shows that the regression lines are not equal or close to the parallel. Although this case is not of the covariance test premises, we can ignore this test because it's not so effective.

To survey the theories of equality and variance

Dependent Variable: pas.faal

\begin{tabular}{|c|c|c|c|}
\hline $\mathrm{F}$ & $\mathrm{df1}$ & $\mathrm{df} 2$ & Sig. \\
\hline, 070 & 1 & 58 &, 793 \\
\hline
\end{tabular}

Tests the null hypothesis that the error variance of the dependent variable is equal across groups.

a. Design: Intercept + piash.faal $+g$

In this chart, which surveys the theories of equality and variances have got the meaningful level more than $5 \%$ have been opposed or different from the variance error.

To survey the adjacency between the dependent and independent variables Dependent Variable: pas.faal

\begin{tabular}{|l|c|c|c|c|c|c|}
\hline Source & Type III Sum of Squares & df & Mean Square & F & Sig. & Partial Eta Squared \\
\hline Corrected Model & $312,715^{a}$ & 2 & 156,358 & 26,641 &, 000 &, 483 \\
Intercept & 499,496 & 1 & 499,496 & 85,107 &, 000 &, 599 \\
piash.faal & 311,898 & 1 & 311,898 & 53,143 &, 000 &, 482 \\
\hline
\end{tabular}




\begin{tabular}{|l|c|c|c|c|c|c|} 
G &, 155 & 1 &, 155 &, 026 &, 872 &, 000 \\
Error & 334,535 & 57 & 5,869 & & & \\
Total & 53751,000 & 60 & & & & \\
Corrected Total & 647,250 & 59 & & & & \\
\hline
\end{tabular}

a. $\mathrm{R}$ Squared $=, 483$ (Adjusted R Squared $=, 465$ )

After getting the medians of pre-test, we get the marks ( $f(68.2)=0.026$ and $p<0.0005 R^{2}$ partial $=0.872$ )

And the effect is a meaningful one. The medians were surveyed again and we got the idea that the information was not completely right. As a result, the accidental helping variable has a meaningful relationship to the dependent variable.

\section{Discussion and Survey of the Project Theory or Premise}

There is a significant different between the teaching methods (traditional and modern ones) in children's aged 4 to 6 and their ability to solve problems in the $12^{\text {th }}$ district of Tehran.

Based on the findings from this project or research, the effectiveness of the traditional and modern methods was well identified. The score of the students taught by the modern methodology were higher than the traditional one.

The findings in this project were exactly the same as Afshari Nezhad (1393), Nakhkoob (1392), Barati (1391), Heidari (1390), Khandan (1389), Alizadeh (1388), Keramati (1380), William and Ainslai (2014), Stephan (2014), Colgru (2012), Millis (2010), Tolimo and etal (2009), Kukak (2008), Ogioglu (2007).

As a whole, Albrich believes that solving problems depends on the equation or the kind of problem, starting them and how to approach the ways to solve them. It is proved that special exercise and drills can increase the intelligence quotient, and so the students will learn much sooner. The logic thinking makes the child avoid answers like "I don't know", "This problem is very hard", etc. or avoids his immediate and thoughtless answers. In this way, the child learns better, under- stands more and solves the more easily.

The essential element in solving the problems is the student's skills and knowledge usage in suitable situations. Because of this fact, bloom has classified kinds of learning and has stressed on the fact that solving a problem is an excellent mind activity and a kind of learning, based on the new psychological approaches, these learners have possessed special cognitive and super cognitive approaches. Wigotsky, too, stresses on the concept of the subjects and the skills learned by the students. He believes that the child instinctively knows how to solve a problem, but if the others (grown up people) help him or her, these skills or abilities will give them more power. In his methodology (i.e. instinctive experimental), wigotsky believes that it's not only the child who solves a problem, but rather it's how change helps the child in this respect. To earn this change, the child learns what is necessary and more than his abilities. In these cases, usually the stimulus which is first a neutral factor, like meaningless words enter as a tool and then act as an agent to change the students' behaviors and functions.

In this respect, William and Ainslai (2014) have done such a research about the students in the pre -school levels and gotten the same results. They got the result that the students who were taught how to solve the problems gains better solutions and easier ones better than the control group.

Also, Stephan (2014) had a research regarding this case, called (solving problems by shares) among the children, based on his findings sharing skills to solve the problems together has had a through and significant effect on the students before school.

It is obvious that the children face different problems during their life periods. These problems need abilities and decisions to be solved. The children may not be able to solve them very well or they may fail in solving them. In this respect, one of the things we could do to help the children is to teach them how to act. Teaching means transferring social and cognitive skills to them. Traditional methods have always been essentially effective. These traditional methods and approaches have been studied and surveyed in this research. In this case, one of the most effective procedures and approaches was active participation of the students in the educational methods at schools. As a matter of fact, these approaches are tools in the hand of the teachers who carefully select them to transfer or teach different concepts such as cognitive and social concepts. Well- known theorists believes that selecting or picking a modern educational approach or method such as a shared one while educational groups is the key solution to many problems. For instance Gardner and Jerom Jweler (2000) claim that in the sharing approach the learners learn from the teacher and also learn from each other. In this way, they relate to each other harder and deeper. They reinforce their listening abilities and learn to concentrate much better.

Afshari Nezhad (1393) has done one of the same researches on the comparison of some functional educational 
approaches and his control or main purpose has been the traditional ways of social and emotional teaching methods on the primary - school students. The result show that the student - oriented method is really effective on the growth, but it has no effect on the social skills, such as the ability to solve problems. In fact, the student- oriented method has been recognized as a modern approach in this research.

Alizadeh (1388), too, has surveyed the effect of solving problems, such as jig-saw puzzles and it's through effect on educational growth and social skills of the students in years 87-88. The result shows that learning in a group has increased and developed social skills among the students.

Social skills growth, cognitive skills growth, reinforcing leadership spirits and sharing skills, correcting social action and developing positivism and optimism are some aspect that are in modern educational methodologies. Indeed, we got the fact that the students in the traditional methods have no sharing activities. When they get into smaller groups which share some educational activities, they learn social and cognitive skills much more easily, so they can solve their problems better.

As a result, we can thoroughly get the fact that one of the elements in today's educational systems that affects students problem solving positive abilities is the methodology. In our country, Iran, although we have had a lot of progress in educational cases, developed our educational spaces and other quantitative measurement more than before, there has been little significant progress on behavioral and communicative developments. Most of the educational centers follow traditional methods and ways. This means students will not be successful in challenging situations because of the lack of suitable experiences. They have little opportunity in cooperative activities, so they have no sharing educational cooperation. In these cases, the students get more and more introvert and nerdy. These days, traditional methods and ways for studies and educational activities are not suitable for students. Traditional methods of teaching just stress on some rote- learning exercises that are obviously repetitive and meaningless; these educational paradigms lack the students' thoughtful action and cause them to be inactive in the educational centers.

Rather, in the modern educational methodologies, the teachers try to make the learning stuff more meaningful, more attractive and more durable for learning. In this environment, the students will grow higher, easier and better. In this respect, the problem solving abilities in the students grow much faster and better. They use modern technology and methodology to live better. They get better results in this situation and will get happier and more skillful.

Children should learn how to cope with the problems and solve them. So, they should learn how to get suitable information and skills to help them in their life. Based on our findings, modern technologies and new teaching methodologies can help students to approach these ideal facts.

In fact, using educational methods can help develop students' abilities in problem solving. In other words, they are necessary for today's life. Active educational ways are using educational concepts and selecting best social and cognitive to solve their problems. Teachers who follow and obey the new, modern technologies and methodologies definitely know that the students entering educational center first don't know how to cooperate and get into collaborative activities. Traditional methods may only transfer superficial information to the students. Lectures are, may only transfer superficial information to the students. Lectures are maybe the most important part of traditional methods. They may not be so useful for learning. These days, we have a booming progress in communication, telecommunication, transportation, social networks and other modern technologies, in this respect, the children should get ready before facing them, let alone, after entering these environments. This millennium has witnessed the fastest developments of all the ages, so we should move shoulder- to- shoulder with the modern world.in this respect, the educational methods have highly changed and developed, so we cannot avoid or ignore these progresses. In other words, if educational centers don't follow the modern technologies, they will lose and face serious challenges. They shouldn't think that the teacher is just the most important factor in education. They shouldn't make students just the inactive or passive members of the education family. They shouldn't depend on old subjects, old and traditional methods of teaching. Rather, they should follow new technologies and obey modern rules in teaching. As a matter of fact, they cannot survive following these old and outdated methodologies foe education.

\section{Research Limitations}

Despite serious and honest efforts to perform the present study in accordance to the rules, this study like other studies has faced problems in the area of human issues that trying to overcome the limitations of future studies, can provide results with confidence and be more confident.

1. The main limitation is harmonizing the clock synchronization of students in kindergarten; such coordination requires a lot of time and energy. 
2. The research has performed for 4 to 6 years old kindergarten children district $12^{\text {th }}$ of Tehran's and cannot be generalized to other age groups.

3. In order to study the variables of the research, questionnaire which was filled out by the trainer, has been used. Completing the questionnaire by the instructor can create restrictions on research, because the number of children in the class is high and there is a low probability of accuracy in completing the questionnaire.

4. The biggest obstacle in the way of researcher is the difficulty of performing tests and unfamiliarity of the trainers with different training methods which leads to the reduction of trainers' cooperation.

5. Implementing new teaching methods (especially participatory method) was very difficult due to the large number of children and the inadequate time provided for the participation of all children in their views and experiences.

6. Discussed teachers' perspective about new methods which was carried out especially for certain activities in this project and their distrust about the results that can be achieved from implementing such projects made the co-investigator harder.

\section{Applicable and Functional Comments}

Given that the effectiveness of new teaching methods in problem-solving abilities of many research and study has been approved, it is better to learn these practices as one of the effective methods to develop children's problem-solving ability and to replace common and traditional teaching-learning methods in kindergartens.

1. It is suggested that related organizations held up workshops for the trainers and teachers to make them familiar with modern teaching methods, to be used continually.

2. It is proposed that by establishing bilateral interactive communication between home and kindergarten notify parents of the tasks more than before and assist them in guiding their children in problem-solving ability.

3. In order to improve problem-solving ability of children by using modern teaching methods, we should codify kindergartens and educational activities in schools' curriculum and in subsequent years (including the purpose, content, methodology and evaluation) to get efficacy results.

4. Authors of training books for 4 to 6 years children, with theoretical and practical knowledge of different traditional and modern teaching- learning approaches, set educational content of the books to achieve more favorable results.

\section{Suggestions for Future Research}

The importance of the present study regarding the importance of investigated issue, many research areas either directly or implicitly can be suggested based on it that some of them are mentioned below:

1. Comparing teaching methods (traditional and modern) in increasing problem-solving ability in various school grades.

2. Comparing teaching methods (traditional and modern) in increasing children's problem-solving ability in other parts of the country

3. Comparing teaching methods (traditional and modern), to increase cognitive strategies 4 to 6 years old children

4. Comparison of teaching methods (traditional and modern) on the self-esteem of 4 to 6 years old children

5. Comparison of teaching methods (traditional and modern) on accretion the problem-solving ability based on demographic variables such as socioeconomic level and...

6. Comparison of teaching methods (traditional and modern) on increasing problem-solving ability in 4 to 6 years old children using tools such as observation and interviews.

\section{References}

Afzali, Leila (2011). The impact of cooperative learning on social behavior and social skills in first-grade elementary students. Master's thesis, MSc of Psychology and Educational Sciences of Tehran University.

Abri, Sare; Rahgozar, Mehdi; Haj Babaie, Hosein; Haj Yoosefi, Ali (2011). Comparing the social development of 3 to 6 years enjoyed or deprived children from the village services; The Case study of Varamin city. Science-Research Journal of Social Welfare, 11 (4).

Kaplan, Paul, S (2000). Developmental Psychology. Translated by Mehrdad FiroozBakht, 2007, Fourth Edition, Tehran: Arasbaran Publish. 
Jafari Kokhaloo, Roghaye; Hamidi, MansourAli (2008). Comparing the benefits of modern and traditional teaching methods, the cognitive, emotional and behavior achievements in high school. Journal of Education, 96.

Kakia, Lida (2009). The effect of preschool education on comprehension and reading speed in the first grade of primary schools in Qom. Journal of efficient schools, 7, 111-104.

AfshariNejad, Seyed Ehsan, (2014). Comparing the efficiency of student-oriented teaching methods with traditional teaching in social skills and emotional development of elementary school students. Master's thesis, MSc of Education Psychology, Ferdowsi University of Mashhad.

Nakhkoob, Maede (2013). Comparing the effectiveness of social skills training and cognitive problem-solving training on the students' aggression having conduct disorder in elementary school in the city of Qom. Master's thesis, MSc of Psychology and Educational Sciences, Isfahan University.

Barati, Hajar (2012). The effectiveness of social skills training on adaptive behavior and social skills of 8 to 12 years girls having Down syndrome. MSc of Psychology and Educational Sciences, University of Welfare and Rehabilitation Sciences.

Heidari, Maryam (2011). The effectiveness of social skills training on first-grade elementary school students of Karaj. Master's thesis, MSc of Humanities PNU Tehran.

Khandan, Farah (2010). The effectiveness of collaborative learning math anxiety and help-seeking behavior, master's thesis, MSc of Psychology and Educational Sciences, Tehran University.

Keramati, MohamadReza (2001). Competition or camaraderie. Journal of Psychology, Vol 31 (2).

Gresham, F. M., Van, M. B., \& Cook, C. R. (2006). Social skills training for teaching replacement behaviors: Remediating acquisition deficits in at-risk students, http/www.Proquest.com.

Erdem, Aliyeh. (2009). Preservice teachers attitudes towards cooperative learning in mathematics course, procedia social and behavioral sciences 1, 1668-1672.

Twerski, R.A., \& Schwartz, U. (2005). Positive parenting. New York: Pearson Company Inc.

William, Dawn \& Aislie, Kristin. (2014). it,s a big problem teaching children solving skills. avalablie in: http: www.minddisorders.com.brdel

Stephen, Erica. (2014). think: rethinking chalenging behavior using collaborative problem solving. avalable in: www.cherrycreekschools. org.cpd.

Millis, Barbara. (2010). Cooperative learning in high education. Publisher: stylus publishing.

Tolmie A.K, Topping, K.J, christic, D, Donaldson,C, Howe, C, Jessiman, E, Livingston,K, Tharston, A. (2009). Social effects of collaborative learning in primary schools. Learning and struction $x \times 1-15$.

Kocak, R. (2008). The effect of cooperative learning on psychological and social traits among undergraduate students. Social Behavior and personality, 36(6), 771-782.

Avgiouglu, Hasan. (2007). Examining the effectiveness of a program developed for teaching social skills to hearing impaired students asked on cooperative learning. Educational sciences: Theory and practice, 7(1). 340-347.

Problem-Solving Ability Questionnaire for 4-6 years old children

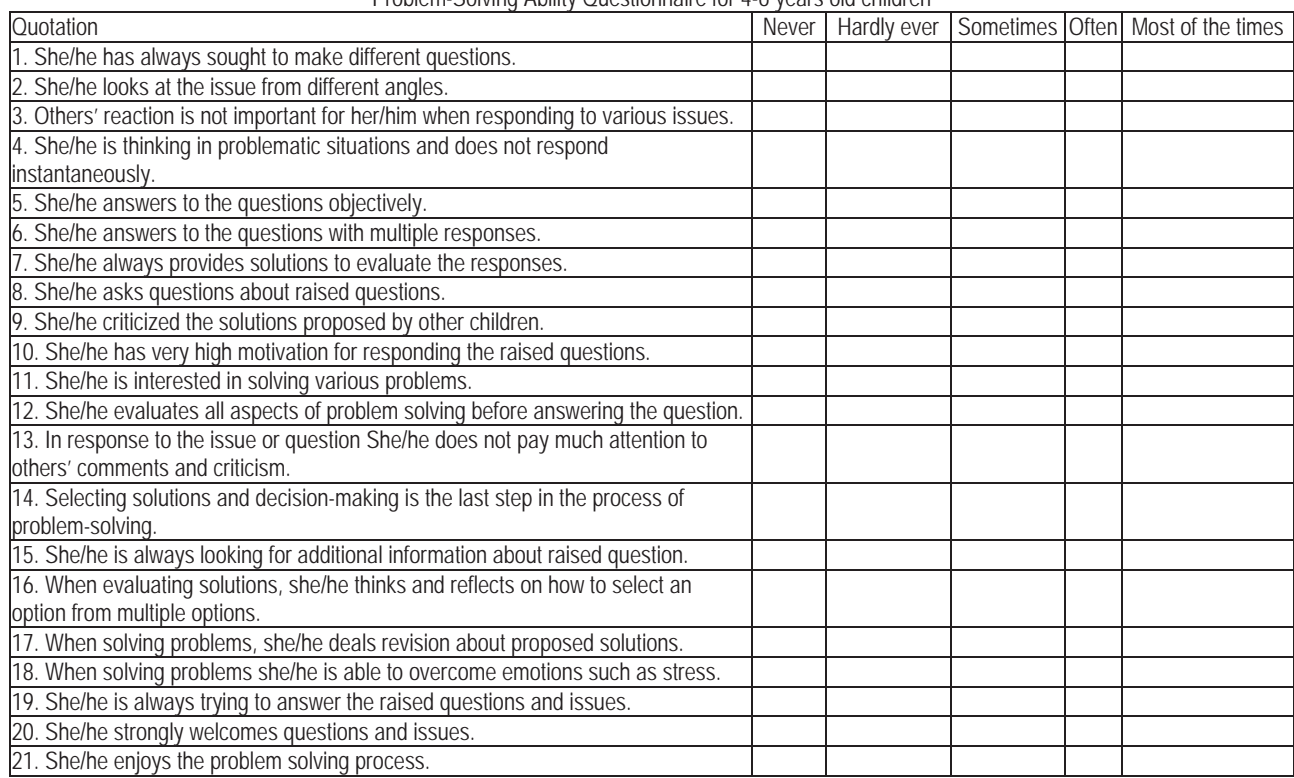

